\title{
Aprendizagem colaborativa: desenvolvimento de Projetos de Aprendizagem em ambientes digitais
}

\author{
Patrícia F. da Silva ${ }^{1}$, Crediné S. de Menezes ${ }^{2}$, Léa da Cruz Fagundes ${ }^{3}$ \\ ${ }^{1}$ PPGIE - Universidade Federal do Rio Grande do Sul (UFRGS) \\ Porto Alegre - RS - Brasil \\ ${ }^{2}$ Departamento de Estudos Básicos - Universidade Federal do Rio Grande do Sul \\ (UFRGS) / Porto Alegre - RS - Brasil \\ ${ }^{3}$ PPGIE - Universidade Federal do Rio Grande do Sul (UFRGS) \\ Porto Alegre - RS - Brasil \\ patriciasilva@lec.ufrgs.br, credine@gmail.com, leafagundes@gmail.com
}

\begin{abstract}
This article describes the work done during the course of "Learning Projects in digital environments "offered in elective for graduate students from different degree courses of the Federal University of Rio Grande do Sul, developed in the first half of 2015. It presents a brief account the context of technologies, work in digital and Learning Project methodology environments, as well as the activities developed during the course, technological inputs used, as was the process of building knowledge and evaluation of the use of the methodology by the students and teachers mediators.
\end{abstract}

Resumo. Este artigo descreve o trabalho desenvolvido durante a disciplina de "Projetos de Aprendizagem em ambientes digitais" oferecida em caráter eletivo para alunos de graduação de diferentes cursos de licenciatura da Universidade Federal do Rio Grande do Sul, desenvolvido no primeiro semestre de 2015. Apresenta um breve relato do contexto das tecnologias, dos trabalhos em ambientes digitais e da metodologia de Projetos de Aprendizagem, bem como as atividades desenvolvidas durante a disciplina, aportes tecnológicos utilizados, como ocorreu o processo de construção de conhecimento e uma avaliação do uso da metodologia por parte dos alunos e dos professores mediadores.

\section{Introdução}

Desenvolver Projetos de Aprendizagem utilizando ambientes digitais, nem sempre é uma tarefa fácil, pois o professor passa de transmissor de conhecimento a mediador, proporcionando interações entre as áreas de conhecimentos e conteúdos de maneira interdisciplinar.

Utilizar metodologias que venham integrar o uso de tecnologias e da aprendizagem a partir do interesse, curiosidade e investigação dos alunos tem se tornado uma ótima opção para um ambiente de aprendizagem colaborativa. Tendo em vista o uso crescente de diferentes recursos tecnológicos no cotidiano e a necessidade de 
oportunizar aos alunos de graduação, futuros educadores, atividades onde a cultura digital seja inserida.

Conforme Fagundes et al (1999), as tecnologias possibilitam trazer para dentro da escola não só as mudanças que estão ocorrendo na sociedade, mas também oferecer oportunidades para que os educadores possam desenvolver práticas inovadoras, visando construir novas competências e talentos.

É comum observar tanto em escolas como em universidades, alunos debruçados sobre cadernos, realizando leituras, marcações de textos, exercícios e até mesmo cópia do quadro e ao final de determinado período retomar os conteúdos dados pelo professor para que possam se preparar para a prova.

No entanto, estudos têm demonstrado, que esta não é a melhor forma para que o aluno possa de fato construir suas aprendizagens e nem mesmo interagir em um ambiente colaborativo, pois copiar, ler, reler e realizar exercícios não é o suficiente para que ele se desequilibre (Piaget, 1976) e comece a procurar por respostas para suas indagações.

Deste modo, através deste artigo apresentamos uma proposta de trabalho que foi realizada durante a disciplina eletiva "Projetos de Aprendizagem em ambientes digitais". Esta proporcionou a construção de ambientes colaborativos, onde a metodologia de Projetos de Aprendizagem pôde ser explorada por alunos de diferentes cursos de licenciatura da Universidade Federal do Rio Grande do Sul.

Este artigo está organizado da seguinte forma: metodologia de Projetos de Aprendizagem, o que é e como se faz, o uso de ambientes digitais e recursos tecnológicos, a metodologia utilizada e o contexto de trabalho, o processo de construção de aprendizagem e como ele acontece, e por fim uma avaliação da disciplina por parte dos alunos e por parte dos professores mediadores.

\section{Projetos de Aprendizagem: o que é e como se faz}

Um dos maiores desafios para a educação é fazer com que os alunos possam aprender a pensar, refletir e buscar de maneira autônoma soluções para problemas que enfrentam no seu cotidiano.

Mas como fazer que os alunos desenvolvam estas habilidades? Que metodologias são adequadas para que eles possam desenvolver a autonomia e o interesse necessário para solucionar conflitos que são considerados relevantes?

De acordo com Fagundes et al (1999), é necessário passar de uma visão empirista de treino e prática, para uma visão construtivista de resolução de problemas, a fim de favorecer a aprendizagem, a interação, busca de informações, comprovação experimental e análise crítica.

As propostas pedagógicas praticadas atualmente, tanto em escolas como universidades, mostram-se de modo geral rígidas e padronizadas, com uma prática baseada em recursos teóricos que exigem dos alunos meras reproduções de conteúdos.

Com o aumento do uso das tecnologias digitais, novas possibilidades de trabalho adentram para as salas de aula, possibilitando aos educadores a implementação de práticas inovadoras que possam viabilizar ao contexto educacional um maior potencial 
para promover aprendizagens, ampliar espaços, diminuir distâncias, vencer as barreiras impostas pelo tempo e ainda possibilitar espaços coletivos de aprendizagem, onde as trocas possam acontecer.

Ao tentar realizar estas mudanças de paradigmas, é preciso observar que a aprendizagem acontece de maneira diferente em cada aluno, pois cada um possui interesses e necessidades diferentes, e o que a escola e a universidade tradicional vêm fazendo ao longo dos anos é ensinar todos da mesma forma; com os mesmos conteúdos e as mesmas sequências didáticas, como se todos os alunos se interessassem pelo mesmo assunto, o que de fato não é verdade.

A metodologia de Projetos de Aprendizagem vem a ser uma atividade construtiva, em que a solução de uma situação problema leva o sujeito a construção de conhecimentos sobre um determinado contexto do qual ele tem interesse em conhecer.

\footnotetext{
Quando falamos em "aprendizagem por projetos" estamos necessariamente nos referindo à formulação de questões pelo autor do projeto, pelo sujeito que vai construir conhecimento. Partimos do princípio de que o aluno nunca é uma tábula rasa, isto é, partimos do princípio de que ele já pensava antes (FAGUNDES et al, 1999, p. 16).
}

Diante de uma questão de investigação que é interesse comum de um grupo de alunos, os autores do projeto que irão construir o conhecimento. Ao elaborar um projeto, os alunos partem dos seus conhecimentos prévios, vão interagir com novas situações, buscar por diferentes informações e fontes, visando se apropriar de um conhecimento específico, as dúvidas conduzem o aluno à busca de respostas e a curiosidade faz com que perturbações aconteçam no sistema de significação do aluno.

A primeira tarefa para iniciar um Projeto de Aprendizagem, é levantar com os alunos as suas certezas provisórias e dúvidas temporárias. Ao pesquisar, questionar e investigar várias dúvidas irão se tornar certezas e certezas também poderão se transformar em dúvidas, um processo de trocas constantes que são organizadas e reorganizadas a todo instante, a cada nova ideia que surge.

Para Piaget (1976), perturbações ocasionadas pelo meio, dificuldades encontradas no processo de assimilação conduzem a desiquilibração e ainda a possibilidade de um processo de reequilibração majorante (recuperação de desiquilibrações), situações estas que compõem o mecanismo do desenvolvimento cognitivo.

Os alunos que se propõem desenvolver um Projeto de Aprendizagem irão formular questões que lhes despertam a curiosidade para as quais tem interesses em buscar respostas, as dúvidas e as respostas são dos alunos, portanto o interesse em buscar resolver estas situações são deles, fazendo com que o conhecimento seja construído a partir das suas curiosidades em saber mais sobre determinado assunto, ou seja, a partir da sua motivação para aprender.

Outro fator importante é o trabalho, que é realizado em equipe, o aluno não é um ser passivo, mas sim ativo, a sua forma de pensar contribui para que ele tenha somente o seu ponto de vista, porém quando se une aos seus colegas poderá ter a possibilidade de enxergar outras formas de pensar e também outros pontos de vista, sendo a cooperação um instrumento necessário para a formação do pensamento racional (Piaget, 1936). 
A cooperação é um método peculiar de uma sociedade que vem se constituindo e implicando a reciprocidade, é um princípio moral e racional essencial para a formação de personalidade. Para que possa aprender, o sujeito necessita descobrir a si próprio e também aprender a se relacionar com os outros.

De acordo com Piaget (1936) no ambiente escolar, jovens e adolescentes por meio da cooperação conseguem sair de um ponto onde só vê o que ele enxerga, construindo um conhecimento mais aprimorado e refinado sobre o universo que está estudando com o confronto de diferentes ideias e formas de pensar do grupo com qual esta trabalhando, tem a possibilidade de misturar, formular e reformular pensamentos, percebendo que através do trabalho em equipe, com diferentes cabeças pensando, poderá ampliar seus conhecimentos. Outras vezes, também é necessário se colocar no lugar do outro, tentando identificar o seu ponto de vista e ainda observa-se a cooperação como fonte de regras para o pensamento, a coerência e seus sistemas de conceitos fazem com que o "eu" passe a pensar no coletivo (Paiget, 1936).

Vê-se, assim sendo, que a cooperação não age somente sobre a tomada de
consciência do indivíduo e sobre o seu senso de objetividade, mas termina,
afinal, por constituir toda uma estrutura normativa que remata sem dúvida o
funcionamento da inteligência individual, mas completando-a no sentido da
reciprocidade - essa norma fundamental que é a única a conduzir o
pensamento racional. Pode-se, pois, dizer, parece-nos que a cooperação é
verdadeiramente criadora, ou, o que vem a ser o mesmo, constitui a condição
indispensável para a completa formação da razão (PIAGET, 1936, p.8).

Observa-se assim, que o trabalho em equipe pode favorecer também o desenvolvimento intelectual, tendo em vista que nos grupos de trabalho as idades dos participantes são diferenciadas, as opiniões a cerca de um mesmo assunto podem variar.

\section{Por que utilizar as tecnologias e os ambientes digitais?}

Para Lévy (1999), uma profunda mutação dos processos de construção do saber vem acompanhada pelo uso crescente das tecnologias digitais e das redes de comunicação, permitindo novas possibilidades de criação coletiva, aprendizado cooperativo e colaborativo.

Estas mutações podem ser observadas tanto em universidades como em escolas, pois ambas estão procurando oportunizar aos alunos a exploração de diversas fontes de conhecimentos que estão acessíveis na internet, o que leva também os educadores a promover atividades diferenciadas, com uso de hipermídias em um ambiente interativo, visando estabelecer assim, novos paradigmas para a construção do conhecimento.

O aluno deverá desenvolver a sua autonomia para que possa se tornar mais ativo e independente, buscando encontrar soluções para resolver os desafios que lhes são propostos, já o professor ao invés de detentor e mero transmissor de conhecimento, passará a ter a função de consultor, mediando às interações entre os alunos, trabalhando de forma interdisciplinar e despertando a tomada de consciência.

Para Resnick (2006), ao invés de trabalhar com disciplinas separadas, é necessário trabalhar com projetos que envolvam todas as disciplinas, oportunizando excelentes conexões entre as mais variadas formas de conhecimento, com alunos de diferentes idades, permitindo que possam aprender uns com os outros. 
V Congresso Brasileiro de Informática na Educação (CBIE 2016)

Anais do XXII Workshop de Informática na Escola (WIE 2016)

A proliferação das tecnologias digitais acentuou a necessidade do pensamento criativo em todos os aspectos da nossa vida, e também forneceu as ferramentas que podem nos ajudar a melhorar e reinventar nós mesmos. Em todo o mundo, as tecnologias de computação e comunicações estão causando um novo espírito empreendedor, a criação de produtos e serviços inovadores, e maior produtividade (RESNICK, 2006, p. 7).

Os espaços colaborativos proporcionam um ambiente onde os alunos podem manifestar a sua criatividade, produtividade e criticidade, trocando ideias e relacionando-se com seus pares, o que muitas vezes pode não ocorrer em ambientes físicos por limitações de tempo e espaço.

\section{A metodologia e contexto de trabalho}

Para dar suporte e viabilizar as práticas e as construções de projetos utilizando a metodologia de Projetos de Aprendizagem em Ambientes Digitais, foi utilizado um ambiente colaborativo do tipo wiki (www.pbworks.com), uma ferramenta de fácil manuseio utilizada para a criação de sites na web, com esta foi criado um site para dar apoio às atividades não presenciais.

O site foi usado para disponibilizar a programação da disciplina, as interações entre os alunos e suas produções individuais. Para cada grupo de projeto, os próprios alunos criaram sites específicos, usando o mesmo ambiente de criação de sites (PBworks), os quais foram linkados ao site principal.

A turma era composta de 11 alunos, todas as informações e atividades estavam descritas já na primeira página da disciplina, permitindo que eles pudessem ir acompanhando e realizando as atividades solicitadas e as oficinas que foram oferecidas conforme a demanda.

Para a maioria dos alunos este estava sendo o primeiro contato com a ferramenta, ainda não haviam utilizado em nenhuma outra disciplina, então foi proporcionado um momento para que pudessem explorá-la e também interagir com os colegas.

Foram indicadas as seguintes leituras: "Aprendizes do Futuro: as inovações começaram"; "O conhecimento como resultado da interação entre o organismo e o meio", "Revisitando os Projetos de Aprendizagem, em tempos de web 2.0" ; "A discussão como ferramenta para o processo de socialização e para a construção do pensamento"4; "O trabalho por equipes na escola" " "Piaget e a nossa inteligência"6.

\footnotetext{
${ }^{1}$ Fagundes, Lea da Cruz. et al. (1999) “Aprendizes do futuro: as inovações começaram!", Coleção Informática para mudança na Educação. http://www.dominiopublico.gov.br/pesquisa/DetalheObraForm.do?select action=\&co obra=40249 .

${ }^{2}$ Piaget, J. (1988) "Psicologia e Epistemologia Genética". In: Ramozzi-Chiarottino, Zelda. São Paulo.

${ }^{3}$ Costa, I. e Magdalena, B. (2008) "Revisitando os Projetos de Aprendizagem, em tempos de web 2.0". http://www.virtual.ufc.br/cursouca/modulo_3/Projetos_SBIE.pdf.

${ }^{4}$ Dayan, S. (2007) "A discussão como ferramenta para o processo de socialização e para a construção do pensamento", Educação em Revista $\mathrm{n}^{\circ}$ 45, Belo Horizonte. http://www.scielo.br/scielo.php?script=sci_arttext\&pid=S0102-46982007000100002.

${ }^{5}$ Piaget, J. (1993) "O trabalho por equipes na escola", Tradução de Luiz G. Feiure. Revista de Educação - Diretoria do Ensino do Estado de São Paulo set/dez 1936. Adaptação para o português moderno: Andrea A. Botelho.
} 
Em uma das sessões presenciais, foi criado um espaço para que os alunos pudessem escrever perguntas interessantes já pensando na elaboração de Projetos de Aprendizagem. Cada aluno deveria contribuir com no mínimo 5 questões que gostariam de se evolver com a busca de respostas, após a data estipulada os grupos foram criados conforme o interesse de escolha das perguntas.

Surgiram no total 44 perguntas em que os alunos teriam interesse em se envolver para pesquisar, elas foram disponibilizadas em um arquivo para escolha e cada um deveria avalia-las com uma nota de 6 (menor interesse) a 10 (maior interesse). As respostas foram tabuladas, com a pontuação dos alunos e a seguir ordenada pela soma de pontos recebidos por cada pergunta. Com isto pode-se apresentar aos alunos, as interseções de interesses para apoiá-los na formação das equipes. Dado que um mesmo aluno podia estar em mais de um possível agrupamento, os alunos dialogaram para definir-se por uma das possíveis equipes. Ao final desta negociação, formaram-se equipes em tornos das questões: "Por que os homens pensam e raciocinam tantos com os intuitos sexuais?", "Como se calcula a paridade cambial entre as moedas?", "Você sabe o que é o senso comum?", "Segundo o Antigo Testamento Moises liderou aproximadamente 600 mil judeus na fuga do Egito em busca da terra prometida. Será que estes números estão certos? Quais eram os meios de comunicação daquela época? Será que podemos fazer uma relação com nossos tempos?”.

As quatro semanas seguintes foram destinadas para a elaboração dos Projetos de Aprendizagem, para tanto foi disponibilizado aos alunos uma sugestão de roteiro para elaboração dos projetos. A primeira etapa consiste no levantamento do conhecimento prévio, que em PA se traduz em termos de "dúvidas temporárias" e "certezas provisórias". Além de listadas, as certezas e dúvidas são representadas em um Mapa Conceitual cuja construção tem por finalidade apoiar a explicitação da teia de conhecimento inicial em torno da questão de investigação.

A pesquisa em um Projeto de Aprendizagem se desenvolve em torno do esclarecimento das dúvidas e da validação/refutação das certezas provisórias. Para fins de da pesquisa convém agrupar esses elementos de forma a constituir-se em unidade de investigação, ou seja, grupos de certezas e dúvidas que podem ser investigadas em conjunto. No qual cada equipe pode pensar sobre, tempo, metodologias e fontes de informação necessária para desenvolvimento de cada unidade de investigação.

Cada equipe criou um espaço de trabalho próprio (usando o PBworks), onde os Projetos de Aprendizagem foram desenvolvidos. Os itens do plano de trabalho foram registrados individualmente em uma nova página, sendo produzido um relatório, onde constavam as fontes consultadas, as discussões e a conclusão do grupo sobre dúvidas temporárias e certezas provisórias e atualização do Mapa Conceitual de cada unidade de investigação.

\footnotetext{
${ }^{6}$ Macedo, L. (1997) "Piaget e nossa inteligência", Material Paradidático Pátio Revista Pedagógica. http://smeduquedecaxias.ri.gov.br/nead/Biblioteca/Forma $\% \mathrm{C} 3 \% \mathrm{~A} 7 \% \mathrm{C} 3 \% \mathrm{~A} 3 \mathrm{o} \% 20 \mathrm{Continuada/Artigos} \%$ 20Diversos/internet/P\%C3\%A1tio\%20Revista\%20Pedag\%C3\%B3gica\%20-\%20Intelig\%C3\%AAncia\%20dimens $\%$ C $3 \%$ B 5 es $\% 20 \mathrm{e} \% 20$ perspec.htm
} 
O grupo 1, definiu desenvolver um Projeto de Aprendizagem com a seguinte Questão de Investigação: "Por que os homens pensam e raciocinam tanto com intuitos sexuais?", para tanto, realizaram buscas na internet, em um livro, uma enquete através do Facebook e questionaram pessoas próximas e conhecidas sobre o assunto. Para os componentes do grupo este projeto possibilitou o esclarecimento de alguns paradigmas inseridos pela cultura, bem como, contar com a opinião e os conhecimentos do colega a fim de resolver o problema de pesquisa, como se observa no excerto a seguir: " $O$ fazer com uma pessoa que tem o mesmo interesse, acrescenta dúvidas e sobre o que estudar, pois com o desenvolver do projeto, gera algumas novas dúvidas e incertezas ao redor do assunto" (Aluna R.C).

Conforme a avaliação dos colegas que visitaram este Projeto de Aprendizagem no espaço colaborativo, o projeto apresentou boas opções de metodologias, pois foram usados diversos textos e também pesquisas com pessoas, presencialmente e online a fim de terem mais opiniões sobre o assunto, apresentou uma boa organização e coerência na organização dos fatos e dos dados pesquisados e ainda possibilitou perceber que o grupo trabalhou de forma colaborativa durante o desenvolvimento do trabalho.

O grupo 2, escolheu desenvolver seu Projeto de Aprendizagem em busca de respostas para a Questão de Investigação: "Como se calcula a paridade cambial entre as moedas?", conforme o grupo, o interesse surgiu a partir da oscilação cambial do real frente ao dólar e ao euro nos últimos tempos. Iniciaram levantando suas certezas e dúvidas acompanhando as variações das moedas que ocorriam diariamente conforme o Banco Central e os registros de jornais durante cinco dias, entrevistas sobre o assunto que foram concedidas em jornais, revistas e na internet. Para o grupo, este projeto possibilitou construir conhecimentos a cerca da história do câmbio e que a paridade cambial é influenciada por diversas situações econômicas de um país, assim como as situações que são externas a este também "acreditamos que novos conhecimentos serão agregados, mas a evolução é incontestável, pois este formato de trabalho, diferente do conhecido, em que cada um realiza uma parte da tarefa, é novidade” (Aluna L.G).

Já na avaliação dos colegas durante a visitação no projeto, o grupo demonstrou ter domínio e propriedade sobre o assunto e ainda fez com que levasse a pensar mais sobre a situação econômica no mundo e como se dá a denominação de valores. $\mathrm{O}$ assunto de economia foi abordado de uma forma diferente, sem se tornar cansativo como em aulas convencionais. Salientaram também que foi possível perceber a organização, envolvimento, trabalho colaborativo e a organização do grupo na construção da página do projeto no espaço virtual.

O grupo 3, selecionou para a sua pesquisa a Questão de Investigação: "Você sabe o que é o senso comum?", porém ao longo da disciplina o grupo acabou sendo desfeito, devido a outras atividades dos participantes e não deram sequência ao trabalho.

O grupo 4, definiu como questão de investigação para seu Projeto de Aprendizagem o bloco de questões: "Segundo o Antigo Testamento Moises liderou aproximadamente 600 mil judeus na fuga do Egito em busca da terra prometida. Será que estes números estão certos? Quais eram os meios de comunicação daquela época? Será que podemos fazer uma relação com nossos tempos?". Para o grupo este tema surgiu devido à passagem do Antigo Testamento da Bíblia, pois gostariam de saber se estes fatos são verídicos ou são fábulas. As pesquisas do grupo para o desenvolvimento 
do projeto e esclarecimento das suas dúvidas e certezas ocorreu através de pesquisas de vídeos, na Bíblia, em reportagens, textos religiosos e também acadêmicos. Para o grupo a cada etapa de realização do projeto, era possível realizar reflexões e trocas sobre o assunto, também foi possível desenvolver todas as partes necessárias para a elaboração de um projeto de aprendizagem e verificar a possibilidade de trabalhar com esta metodologia no contexto educacional, "gostei muito do método ou processo empregado e se um dia tiver a oportunidade, com certeza que eu aplicarei aos alunos. Através deste projeto me fez pensar em como conhecer, compreender e progredir na resolução dos problemas" (Aluno E.V.).

Durante a visitação do projeto, os colegas afirmaram que este projeto possui grande complexidade, levou-os a questionar-se ainda mais sobre as explicações dadas pela ciência, e também que para este assunto, é bem interessante o uso de vídeos, mídias e dos mapas conceituais, para ajudar a entender a temática. Foi destacado também, que foi possível observar o envolvimento do grupo durante o trabalho, mas que para melhor organização do material pesquisado, a página criada no PBworks para o projeto, deveria ser melhor organizada, para que facilitasse encontrar as etapas e a visualização da pesquisa.

A socialização dos Projetos de Aprendizagem foi realizada através de uma apresentação oral, os alunos puderem escolher uma ferramenta de apresentação, do tipo Power Point ou Prezzi para mostrar aos colegas os processos de sua pesquisa, suas experiências, as dificuldades e as conclusões a que chegaram. Posteriormente foram oportunizados espaços para que acontecesse a visitação dos projetos, as avaliações individuais e dos grupos.

\section{A avaliação da disciplina pelos alunos e pelos professores mediadores}

Para todos os alunos este foi o primeiro contato com a metodologia de Projetos de Aprendizagem e em geral, conforme os relatos das avaliações individuais, esta metodologia mostrou-se eficaz e o trabalho colaborativo fez com que os alunos percebessem a importância de trocar informações, obter um ritmo para 0 desenvolvimento do projeto e também a possibilidade de compartilhar conhecimentos.

As ferramentas utilizadas para a apresentação dos projetos, organização e elaboração de Mapas Conceituais puderam contribuir para que as informações fossem encontradas e pudessem dar uma sequência ao trabalho.

Trabalhar com ferramentas que possibilitassem desenvolver as tarefas a distância, também foi apontado pelos alunos como um fator relevante, pois possibilitou que eles pudessem desenvolver as atividades sem a necessidade de estarem presentes em mesmo horário e local.

Os Projetos de Aprendizagem foram vistos pelos alunos como algo trabalhoso, que deve ser bem pensado e organizado, pois exige bastante pesquisa e também trabalho em equipe, fazendo com que interesses, dúvidas e certezas gerem novos conhecimentos.

$\mathrm{Na}$ visão dos professores mediadores da disciplina de Projetos de Aprendizagem em ambientes digitais, oportunizou um ótimo momento para construção de conhecimentos entre os alunos e mediadores, foi possível identificar as dúvidas dos 
V Congresso Brasileiro de Informática na Educação (CBIE 2016)

Anais do XXII Workshop de Informática na Escola (WIE 2016)

alunos em relação ao trabalho com esta metodologia nas escolas e também as maiores dificuldades e receios ao trabalhar com recursos digitais no contexto escolar.

De acordo com o relato dos alunos, a disciplina foi muito proveitosa, mostrando uma nova possibilidade de trabalho no contexto escolar, utilizando os interesses dos alunos e recursos tecnológicos que eles certamente não encontraram dificuldades em explorar.

Outro fato que chamou a atenção foi o depoimento de vários alunos sugerindo que esta é uma disciplina que deveria ser considerada como obrigatória, pois a maior parte deles já estava no final dos seus cursos e ainda não haviam tido contato com estes recursos e com a metodologia, e até então não utilizavam em suas salas de aula, como professor regente ou estagiário. Sendo assim, foi possível verificar que está é uma metodologia bem aceita por alunos de graduação e que possivelmente será levada para a sala de aula dos alunos.

\section{Referências}

Costa, I. e Magdalena, B. (2008) "Revisitando os Projetos de Aprendizagem, em tempos de web 2.0". http://www.virtual.ufc.br/cursouca/modulo_3/Projetos_SBIE.pdf. Maio.

Dayan, S. (2007) "A discussão como ferramenta para o processo de socialização e para a construção do pensamento", Educação em Revista no 45, Belo Horizonte. http://www.scielo.br/scielo.php?script=sci arttext\&pid=S0102-46982007000100002. Maio.

Fagundes, Lea da Cruz. et al. (1999) “Aprendizes do futuro: as inovações começaram!”, Coleção Informática para a mudança na Educação. http://www.dominiopublico.gov.br/pesquisa/DetalheObraForm.do?select_action=\&c o obra $=40249$. Maio.

Lévy, P. (1999) "Cibercultura”, Tradução de Carlos Irineu da Costa, Editora 34, São Paulo. Abril.

Macedo, L. (1997) "Piaget e nossa inteligência", Material Paradidático Pátio Revista Pedagógica.

http://smeduquedecaxias.ri.gov.br/nead/Biblioteca/Forma $\% \mathrm{C} 3 \% \mathrm{~A} 7 \% \mathrm{C} 3 \% \mathrm{~A} 3 \mathrm{o} \% 20 \mathrm{C}$ ontinuada/Artigos $\% 20$ Diversos/internet/P\%C3\%A1tio\%20Revista $\% 20 \mathrm{Pedag} \% \mathrm{C} 3 \%$ B3gica $\% 20-\% 20$ Intelig\%C3\%AAncia\%20dimens $\% \mathrm{C} 3 \% \mathrm{~B} 5 \mathrm{es} \% 20 \mathrm{e} \% 20$ perspec.htm. Maio.

Piaget, J. (1976) “A equilibração das estruturas cognitivas: problema central do desenvolvimento", Zahar Editores, Rio de Janeiro. Abril.

Piaget, J. (1988) "Psicologia e Epistemologia Genética". In: Ramozzi-Chiarottino, Zelda. São Paulo. Maio.

Piaget, J. (1993) "O trabalho por equipes na escola", Tradução de Luiz G. Feiure. Revista de Educação - Diretoria do Ensino do Estado de São Paulo set/dez 1936. Adaptação para o português moderno: Andrea A. Botelho. Maio 
V Congresso Brasileiro de Informática na Educação (CBIE 2016)

Anais do XXII Workshop de Informática na Escola (WIE 2016)

Resnick, M. (2006), "Repensando o Aprendizado na Era Digital”, Workshop Scratch e Cricket: novos ambientes de aprendizagem e de criatividade. Bradesco Instituto de Tecnologia. https://llk.media.mit.edu/papers/rethinkport.doc. Abril. 